03, 13

\title{
Выращивание объёмных кристаллов AIN и GaN сублимационным сандвич-методом
}

\author{
(C) Е.Н. Мохов, А.А. Вольфрсон, О.П. Казарова \\ ${ }^{1}$ Физико-технический институт им. А.Ф. Иофрфе РАН, \\ Санкт-Петербург, Россия \\ E-mail: mokhov@mail.ioffe.ru
}

Поступила в Редакцию 16 июля 2019 г.

В окончательной редакции 16 июля 2019 г.

Принята к публикации 25 июля 2019 г.

\begin{abstract}
Приведен обзор результатов роста объемных кристаллов нитридов Al и Ga на инородных затравках сублимационным сандвич-методом. Анализируется кинетика и механизм сублимации и конденсации в зависимости от условий роста, состава паровой фазы, ориентации кристалла и расстояния между источником и затравкой. Экспериментально установлено, что при совместном отжиге AlN c SiC скорость сублимации AlN существенно возрастает за счет образования жидкой фазы на поверхности кристалла. Неоднородное распределение жидкой фазы, локализованной преимущественно вблизи структурных и морфологических дефектов, приводит к селективному характеру травления поверхности и является причиной ухудшения качества растущего кристалла. Реализован процесс роста объемных кристаллов AlN с одновременным испарением затравки, позволяющий получить кристаллы без трещин и с улучшенными параметрами. На затравках $\mathrm{SiC}$ выращены объемные кристаллы $\mathrm{AlN}$ и $\mathrm{GaN}$ до 2 дюймов в диаметре.
\end{abstract}

Ключевые слова: $\mathrm{AlN}, \mathrm{GaN}$, сублимационный рост, сандвич-метод.

DOI: 10.21883/FTT.2019.12.48537.17ks

\section{1. Введение}

Нитриды металлов III группы (AlN, GaN, InN и их твердые растворы) обладают уникальным сочетанием физических свойств, которые гарантируют их востребованность в современной микро- и оптоэлектронике [1]. К числу этих свойств относятся большая ширина запрещённой зоны, высокая дрейфовая скорость насыщения, высокое напряжение пробоя, высокая теплопроводность, замечательная химическая и термическая стойкость и т.д. Благодаря этим характеристикам нитриды в настоящее время рассматриваются как наиболее перспективные материалы для создания мощных высокочастотных транзисторных структур, способных функционировать при высоких температурах и в агрессивных средах. Приборы такого типа могут использоваться в беспроводных системах связи, системах переключения в энергетике, детекторах быстрого обнаружения химического или биологического заражения и т.д. Однако наибольшие ожидания в связи с развитием нитридных технологий относятся к твердотельным источникам света, включая коротковолновые светодиоды и лазеры видимого и УФ диапазонов, а также базовые УФ элементы ярких „белых“ светодиодов. Также актуально их использование для изготовления мощных высокочастотных транзисторов и УФ фотодетекторов, способных работать при повышенных температурах и в агрессивных средах. Для реализации этих несомненных достоинств нитридов требуется обеспечить выращивание объемных кристаллов высокого качества, диаметром $50 \mathrm{~mm}$ и более, для использования в качестве подложек.
Росту объемных кристаллов нитридов посвящен ряд публикаций, которые нашли свое отражение в отличных обзорах, например [2]. Недостатки большинства этих методов обусловлены сравнительно низкими температурами роста, при которых вероятно образование на поверхности подложки большого числа отдельных центров кристаллизации. К тому же, рост ведется в присутствии химически активных примесей, создающих примесный хемосорбат, как правило, затрудняющий латеральное перемещение атомов по поверхности. Высокое содержание примесей приводит также к их частичному захвату кристаллом с образованием включений второй фазы. От этих недостатков свободен сублимационный метод роста (или PVT - physical vapor transport), в котором транспортеры не используются. Поэтому PVT - выращивание обеспечивает монокристаллический рост с более высокими скоростями, чем другие методы [2].

Основной проблемой при создании нового поколения приборов на основе нитридов является отсутствие высококачественных затравок $\mathrm{GaN}$ и $\mathrm{AlN}$ требуемых размеров.

В настоящей работе сообщается о PVT росте объемных кристаллов нитридов $\mathrm{Al}$ и $\mathrm{Ga}$ сублимационным сандвич-методом (ССМ) [3], Анализируются кинетика и механизм сублимации и конденсации нитридов в сандвич-ячейке в зависимости от состояния источника, условий проведения процесса, с целью оптимизации условий кристаллизации. Показано, что образование жидкого слоя на поверхности источника и затравки 


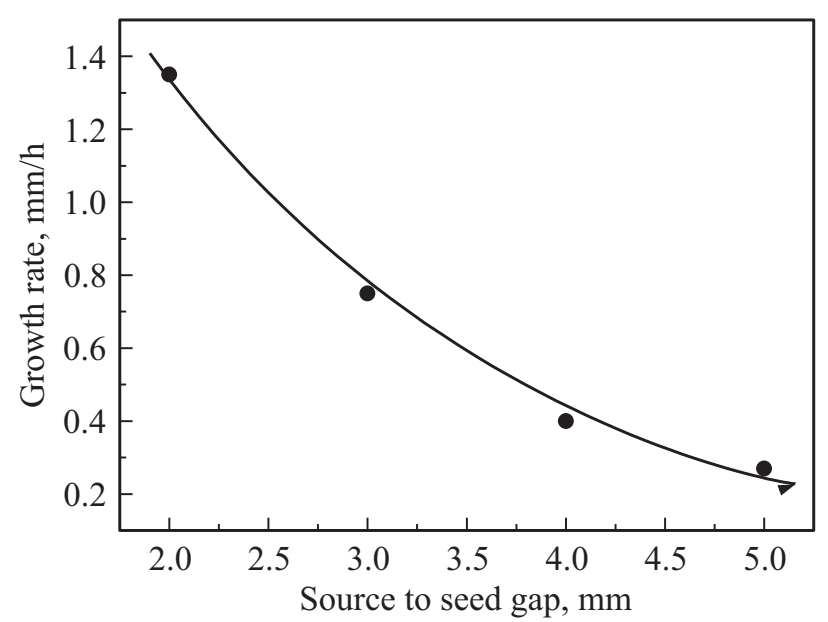

Рис. 1. Зависимость скорости роста $\mathrm{GaN}$ от расстояния между источником и затравкой.Температура подложки $-1200^{\circ} \mathrm{C}$.

позволяет повысить эффективность массопереноса и улучшить качество растущего кристалла.

\section{2. Эксперимент}

Аппаратура для выращивания кристаллов AlN и GaN описана ранее $[4,5]$. Необходимо отметить, что вследствие низкой температуры разложения $\mathrm{GaN}$, рост $\mathrm{GaN}$ ведут в открытой системе в протоке аммиака при температуре $1100-1200^{\circ} \mathrm{C}$.

Рост объемных кристаллов AlN осуществляют в замкнутых контейнерах, изготовленных из карбидизированного тантала в атмосфере азота при температуре $1950-2100^{\circ} \mathrm{C}$. Давление азота варьировалось в пределах $10^{-2}-10^{\circ} \mathrm{atm}$.

Для выращивания слитков обычно используются монокристаллические затравки из $\mathrm{SiC}$ политипов $4 \mathrm{H}$ или $6 \mathrm{H}$ в виде дисков диаметром 55-60 mm.

В качестве сублимирующего источника обычно применяется порошок GaN или AlN. Однако, в этом случае скорость конденсации оказывается недостаточно высокой и резко уменьшается со временем. Было установлено [5], что повышение скорости роста можно достигнуть путем добавления в источник металлического Ga или $\mathrm{Al}$. Более того, наиболее перспективными для роста $\mathrm{GaN}$ оказались источники из металлического $\mathrm{Ga}$.

Зависимость скорости роста от расстояния до затравки $(\Delta x)$ для такого источника приведена на рис. 1 . Видно, что достаточно высокие скорости роста достигаются только при относительно малых $\Delta x$, порядка $2-4 \mathrm{~mm}$. Теоретический анализ показал, что экспериментально наблюдаемая зависимость $V(\Delta x)$ не объясняется в рамках модели массопереноса в диффузионном режиме. При этом экспериментально наблюдаемая скорость роста почти на порядок превышает расчетную скорость испарения $\mathrm{Ga}$. Полученные результаты были объяснены тем, что при нагреве расплава $\mathrm{Ga}$ в потоке аммиака поверхность жидкости теряет устойчивость и происходит разбрызгивание галлия, который в виде отдельных капель попадает на поверхность затравки. Таким образом, обеспечивается массоперенос $\mathrm{Ga}$, который далее связывается с азотом, образуя слой $\mathrm{GaN}$. Важно отметить, что присутствие жидкого Ga на растущей поверхности способствует качественному росту кристалла $\mathrm{GaN}$ с предельно высокими скоростями (до $1 \mathrm{~mm} / \mathrm{h}$ ) [5]. Высокое качество кристаллов подтверждается результатами рентгено-дифракционных измерений, а также анализом спектров люминесценции и электронно-парамагнитного анализа (ЭПР) [5].

Резкое повышение скорости роста наблюдается и при сублимационном росте $\mathrm{AlN}$, когда в качестве источника используется расплав $\mathrm{Al}$ [6]. Однако, такой процесс трудно осуществить для роста объемных кристаллов, вследствие высокой агрессивности жидкого алюминия по отношению к материалу контейнера.

Однако, в дальнейшем было показано [5], что эффект увеличения скорости роста имеет место также при использовании источника $\mathrm{AlN}$, в который дополнительно вводятся кремний или $\mathrm{SiC}$. В частности, при добавлении в источник $\mathrm{SiC}$ скорость сублимации $\mathrm{AlN}$ возрастает в 5-10 раз, что позволяет снизить температуру сублимационного роста $\mathrm{AlN}$ на $150-200^{\circ} \mathrm{C}$ по сравнению с ростом AlN в чистых условиях [2].

Дополнительное исследование позволило выявить признаки существования жидкой фазы на поверхностях, как источника, так и затравки. Так, при быстром охлаждении на поверхности обнаруживались каплеподобные образования (рис. 2), которые находились в углублениях (ямках). С увеличением времени охлаждения размеры углублений возрастали, нередко они трансформировались в весьма протяженные канавки или дырки. Изучение рамановских спектров позволило установить, что в состав капелек входит свободный кремний.

Существенное влияние на перенос вещества от источника к затравке в сандвич системе оказывает давление азота (рис. 3). Видно, что наиболее полный перенос, при котором $K_{t}=1$, (где $K_{t}$ - коэффициент переноса AlN) достигается только при относительно высоком давлении азота (выше $0.2 \mathrm{~atm}$ ). Снижение эффективности переноса, очевидно, обусловлено низким коэффициентом прилипания (sticking coefficient) к поверхности затравки молекулярного азота [7]. Коэффициент переноса также уменьшается при снижении перепада температуры между источником и затравкой (рис. 4).

\section{3. Результаты и их обсуждение}

Известно, что сублимация нитридов - процесс достаточно сложный, и для корреляции экспериментально наблюдаемых скоростей испарения с расчетными данными требуется введение кинетических ограничений в виде коэффициентов испарения. Коэффициенты испарения 
$a$
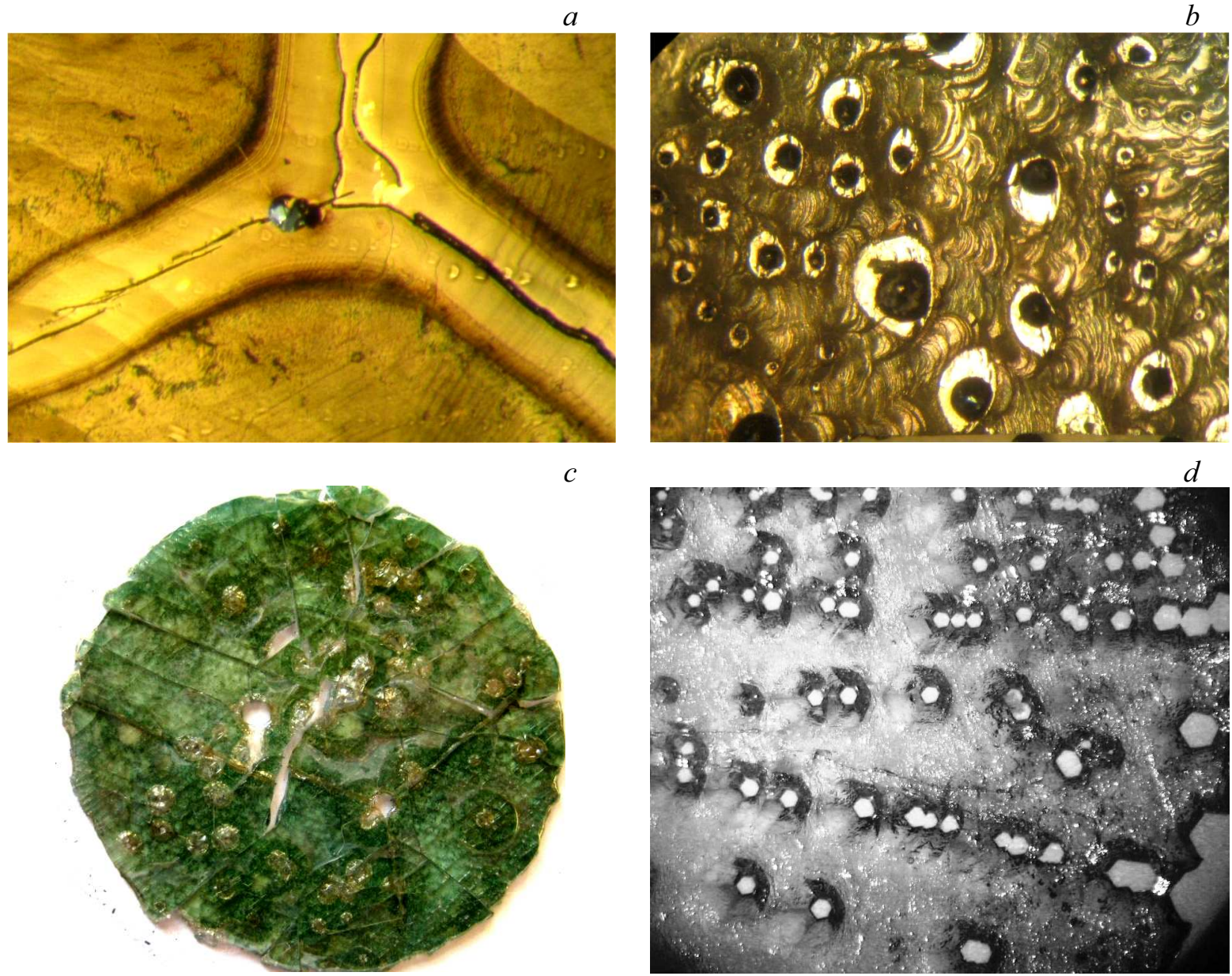

$c$

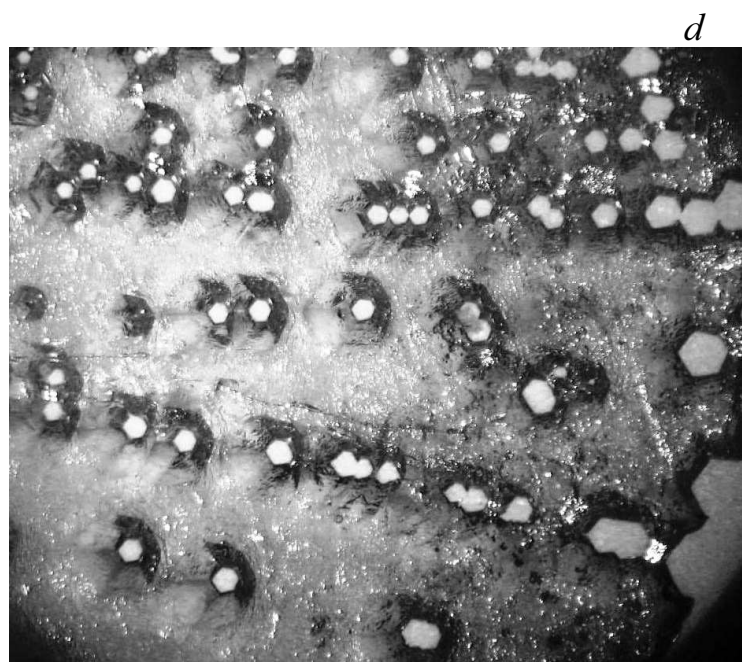

Рис. 2. Каплеподобные образования $(a, b)$ и селективное травление $(c, d)$ на ростовой $(a, c)$ и испаряемой $(b, d)$ поверхностях монокристаллов AlN. Температура роста $-2000^{\circ} \mathrm{C}$, время охлаждения $-10 \mathrm{~min}(a, b) ; 1 \mathrm{~h}(c, d)$.

для нитридов аномально низки и находятся в пределах $10^{-3}-10^{-5}$ [8]. Но в реальной системе содержатся примеси, в первую очередь кислород и углерод, которые могут весьма существенно влиять на массоперенос AlN.

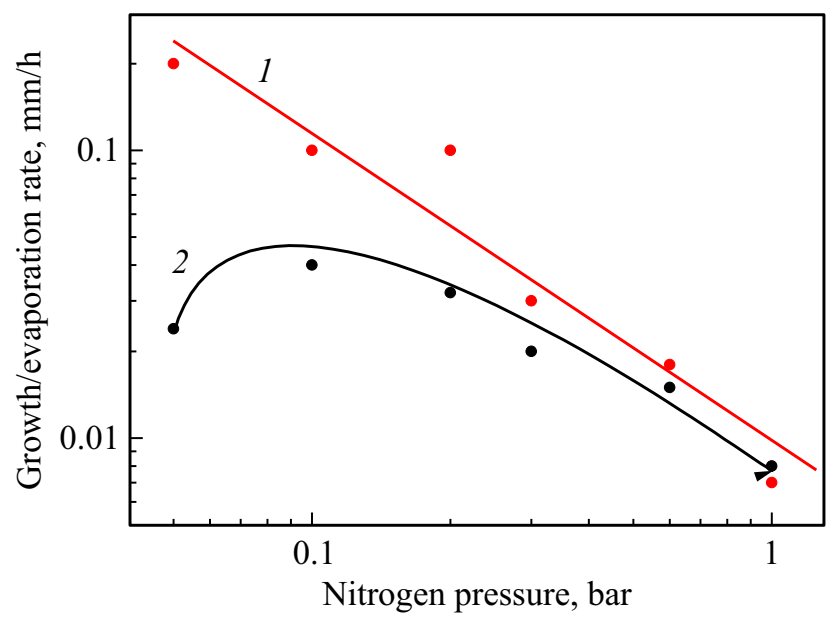

Рис. 3. Зависимость скорости испарения (1)и роста (2) AlN от давления азота. Температура роста $-1980^{\circ} \mathrm{C}$.
Нитриды галлия и особенно алюминия легко окисляются на воздухе. Поэтому коммерческие порошки нитридов, используемые в качестве источника, всегда содержат большое количество кислорода (до 10\%).

Нами изучалась скорость сублимации поликристаллического AlN различного происхождения. Испаряемый порошок помещался в контейнеры из ТaC, предназначенные для роста кристаллов AlN. Температура отжига $\left(T_{a}\right)$ варьировалась от 1800 до $2300^{\circ} \mathrm{C}$, продолжительность отжига составляла от 1 до $10 \mathrm{~h}$. При температуре $1800^{\circ} \mathrm{C}$ отжиг велся в вакууме, а при более высоких - в среде азота. Скорость испарения контролировалась по изменению веса и толщины исходного кристалла.

Предполагается, что равновесный пар над $\mathrm{GaN}$ и AlN состоит только из атомов металла и молекул азота $\left(\mathrm{N}_{2}\right)$. В случае AlN при температурах роста $1900-2300^{\circ} \mathrm{C}$ упругость паров $\mathrm{Al}$ достаточно высокая и предполагается, что коэффициент захвата Al близок к единице. Напротив, коэффициент захвата молекулярного азота очень мал, порядка $10^{-5}-10^{-6}$, при температурах роста AlN [9]. 


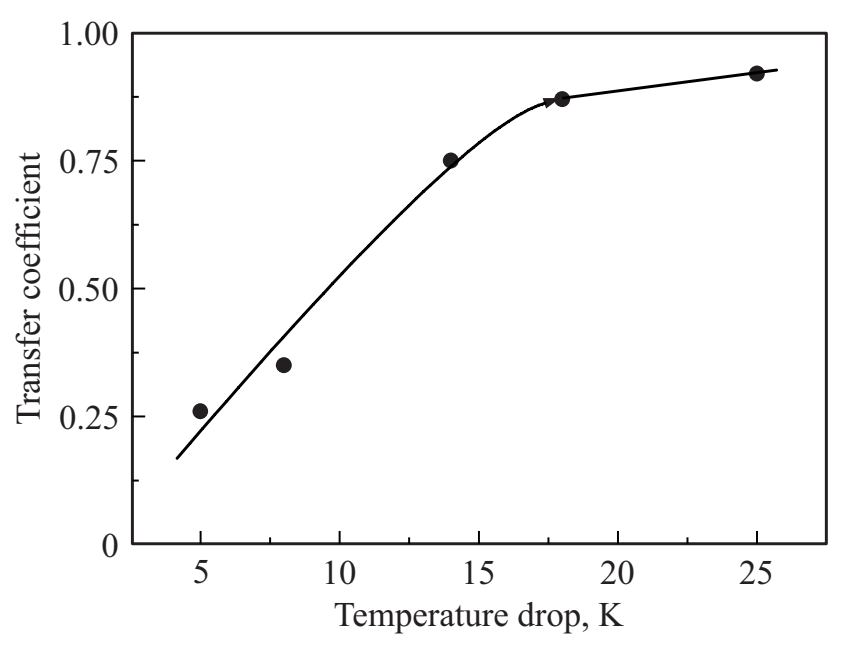

Рис. 4. Зависимость коэффициента переноса $\mathrm{AlN}$ в сандвичячейке от перепада температур между источником и затравкой.

Известно, что молекулы азота - чрезвычайно прочные, время жизни их на поверхности растущего кристалла чрезвычайно мало, что и обуславливает низкие коэффициенты конденсации молекул $\mathrm{N}_{2}$ при сублимационном росте. Именно, низкая эффективность захвата азота является причиной того, что сублимационный рост нитридов (в отличие от роста $\mathrm{SiC}$ ) трудно осуществим в вакууме или в атмосфере инертного газа. Обычно кристаллы нитридов выращиваются в среде азота $\left(\mathrm{N}_{2}\right.$ или $\mathrm{NH}_{3}$ ), при относительно высоких парциальных давлениях азота (значительно больших, чем равновесное давление), поэтому в случае $\mathrm{GaN}$ сублимационный рост возможен лишь при введении активного азота $\left(\mathrm{NH}_{3}\right)$.

Низкие коэффициенты захвата азота приводят к тому, что расширяется диапазон давлений азота, при которых скорость роста лимитируется не диффузионным перено- сом через паровую фазу, а поверхностными реакциями. Для процесса, лимитируемого диффузией, выполняется соотношение $V=A P^{-1}(V-$ скорость роста, $P-$ давление азота, $A-$ константа, зависящая от условий роста и состояния поверхности). При молекулярно кинетических режимах роста зависимость от давления или более слабая, или скорость не зависит от давления.

При анализе кинетики массопереноса следует учитывать влияние различных факторов. Во-первых, теоретические и экспериментальные данные свидетельствуют, что нитриды AlN и GaN с повышенным содержанием кислорода обладают наиболее высокой скоростью испарения. В процессе отжига содержание кислорода заметно снижается, что и обуславливает изменение скорости сублимации.

Пересублимированный источник AlN, как наиболее чистый по кислороду, характеризовался минимальной скоростью испарения. Таким образом, подтверждаются выводы теоретических работ - кислород ускоряет массоперенос, являясь транспортером AlN. Дальнейшие исследования роста AlN с использованием источника с разным содержанием кислорода показали, что качество растущего кристалла ухудшается с увеличением содержания кислорода в источнике. Поэтому при росте желательно использовать наиболее чистый источник.

Bo-вторых, на скорость сублимации AlN и GaN влияет введение металлов - $\mathrm{Al}$ или $\mathrm{Ga}$, а также $\mathrm{Si}$, находящихся при температуре роста в жидком состоянии.

Проведенные исследования выявили также существенное увеличение скорости сублимации AlN при введении в систему $\mathrm{SiC}$.

Наиболее корректным выглядит объяснение ускоренноой сублимации, а следовательно и роста нитридов в этом случае присутствием на поверхности жидкой фазы. Жидкая фаза, очевидно, образуется как на испаряемой, так и на ростовой поверхности. Она может существо-

$a$
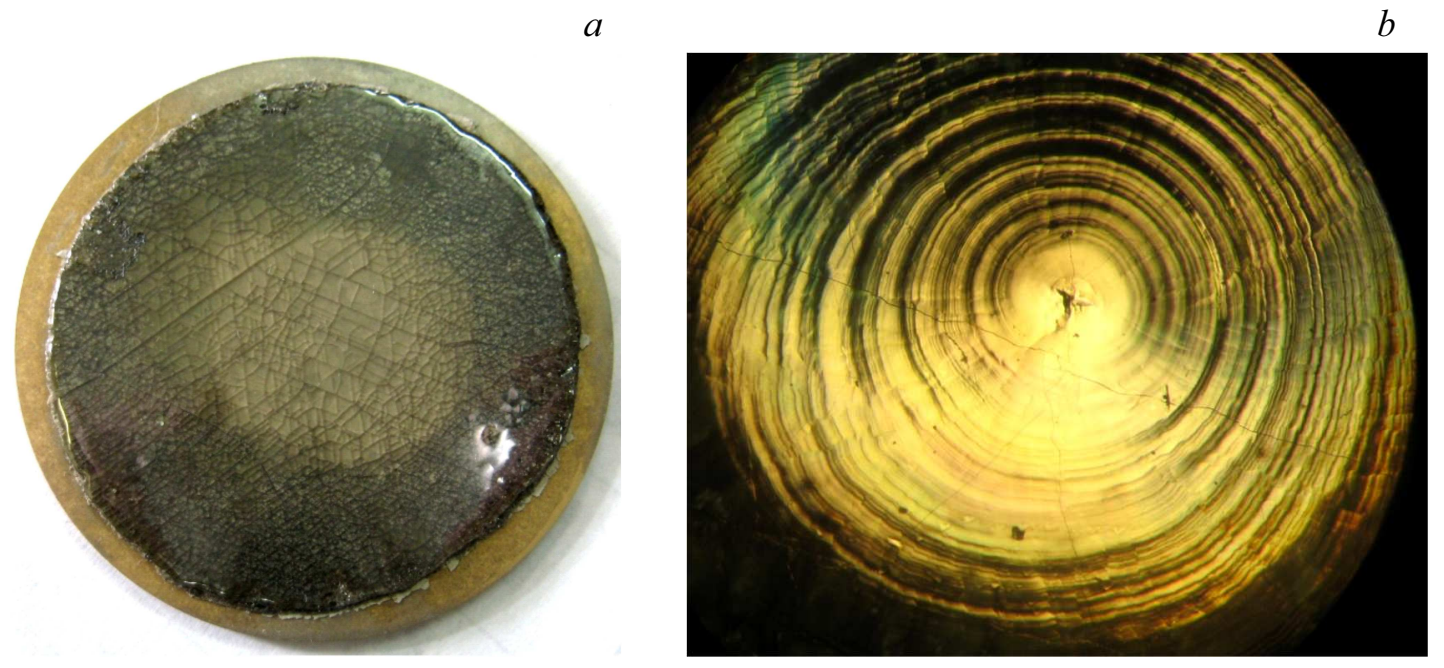

Рис. 5. Вид двухдюймового кристалла $\mathrm{AlN}$, выращенного на $\mathrm{SiC}$ затравке после удаления затравки $(a)$ и морфология ростовой поверхности $(b)$, свидетельствующая о слоевом механизме роста 
вать на поверхности в виде тонкого слоя или в виде отдельных капель. Образование равномерного тонкого слоя, в целом, благоприятно для роста кристалла, т.к. облегчается коалесценция возникающих зародышей и, следовательно, снижается их плотность, что способствует слоевому механизму роста (рис. $5, b$ ). Однако возникновение капель на ростовой поверхности, наблюдаемое при снижении температуры на стадии охлаждения, очевидно, приводит к образованию пор и канавок, за счет селективного травления растущей и испаряемой поверхностей (рис. 2).

\section{4. Заключение}

Рассмотрены условия роста, состав паровой фазы и необходимая величина зазора между источником и подложкой. Установлено, что в присутствии $\mathrm{SiC}$ скорость сублимации AlN значительно возрастает благодаря образованию на поверхности жидкой фазы. Реализован процесс роста объёмных кристаллов A1N с одновременным испарением подложки, что позволило получить кристаллы лучшего качества, не имеющие трещин. На подложках $\mathrm{SiC}$ выращены объёмные кристаллы AlN диметром до 2 дюймов. Дан обзор результатов получения объёмных кристаллов нитридов $\mathrm{Al}$ и $\mathrm{Ga}$ на инородных подложках с помощью сублимационного сандвич- метода. Рассмотрены кинетика и механизм сублимации конденсации этих нитридов.

\section{Конфликт интересов}

Авторы подтверждают, что у них нет конфликта интересов.

\section{Список литературы}

[1] H. Markoc, S. Strite, G.B. Gao, M.E. Lin, B. Sverdlov, M. Burns. J. Appl. Phys. 76, 1363 (1994).

[2] C. Hartmann, A. Dittmar, J. Wollweber, M. Bickermann. Sci. Technol. 29, 084002 (2014).

[3] Yu.A. Vodakov, E.N. Mokhov. Patent UK: No 1458445 (1977).

[4] O.V. Avdeev, T.Yu. Chemekova, H. Helava, M.G. Ramm, Yu.N. Makarov, E.N. Mokhov, S.S. Nagalyuk, A.S. Segal. Comprehensive Semiconductor Science and Technology. Elsevier. (2011). P. 282-301.

[5] E.N. Mokhov, A.A. Wolfson. In book: Single Crystals of Electronic Materials: Growth and Properties. Editted by Roberto Fornari. Woodhead Publishing. (2018). P. 401-445.

[6] P.T. Wu, M. Funato, Y. Kawakami. Sci. Rep. 5, 17405 (2015).

[7] S.Yu. Karpov, A.V. Kulik, M.S. Ramm, E.N. Mokhov, A.D. Roenkov, Yu.A. Vodakov, Yu.N. Makarov. Mater. Sci. Forum. 353356, 779 (2001).

[8] Z.Y. Fan, N. Newman. Mater. Sci. Engineering. B. 87, 244 (2001).

[9] S.G. Mueller, R.T. Bondokov, K.E. Morgan, G.A. Slack, S.B. Schujman, J. Grandusky, J.A. Smart, L.J. Schowalter. Phys. Status Sol. A 206, 1153 (2009).

Редактор Т.Н. Василевская 